\title{
DEVELOPMENT PARTNERS IN DISSEMINATING PARLIAMENTARY INFORMATION IN ZIMBABWE: CONTRIBUTIONS AND CHALLENGES
}

\section{Isaiah Munyoro}

Department of Information Science

University of Pretoria

Pretoria, South Africa

munyorois@gmail.com

\section{Archie L. Dick}

Department of Information Science

University of Pretoria

Pretoria, South Africa

archie.dick@up.ac.za

\section{ABSTRACT}

United Nations agencies and civil society organisations (CSOs) are working as development partners (DPs) with parliaments across the globe. They are engaged in activities to strengthen parliaments in both developed and developing countries. Data from a study that evaluated the performance of Zimbabwe's Parliamentary Constituency Information Centres (PCICs) showed that DPs play important roles in disseminating parliamentary information to constituents.

\section{UNISA $\cong$}


This article analyses the contributions by the United Nations Development Programme (UNDP) and the International Network for the Availability of Scientific Publications (INASP), and the challenges they face in Zimbabwe.

KEYWORDS: development partners, civil society organisations, information dissemination, Parliamentary Constituency Information Centres, Zimbabwe

\section{INTRODUCTION}

In carrying out their central functions, parliaments collaborate with a number of development partners (DPs) to uphold and safeguard the democratic rights of citizens. DPs refer to United Nations agencies and civil society organisations (CSOs) engaged in strengthening parliamentary work (Granickas 2013). These DPs play vital roles in assisting parliaments to disseminate relevant parliamentary information to their constituents. Through collaboration with the parliaments, for example, DPs ascertain and assess public opinion on parliamentary information needs that range from constituents' understanding of how parliament works to updating their knowledge on the full spectrum of government operations. They also collect information on how issues affecting constituencies are being addressed. The majority of Zimbabwean constituents face challenges, such as the lack of access to water, food, education, health care, sanitation, as well as information. As a consequence, DPs with different competencies have moved into Zimbabwe to assist in the dissemination of parliamentary information. This has been achieved in several ways. An evaluation report of the United Nations Development Programme (UNDP) parliamentary support project in Zimbabwe (De Vrieze and Murapa 2012) revealed that the Parliamentary Constituency Information Centres (PCICs) - which disseminate parliamentary information to constituents - are one of the projects. The PoZ has received funding from DPs, such as the UNDP, the Konrad Adenauer Foundation (KAF), and the Swedish International Development Agency (SIDA). SIDA funded the first feasibility study on the establishment of PCICs (Mutaviri and Ncube 2003) and the UNDP bought furniture and information and communications technology (ICT) equipment, and paid salaries for office assistants (OAs) and rates for rented PCIC offices.

\section{PROBLEM STATEMENT}

The PoZ has a large amount of information of which constituents are unaware. A number of parliamentary departments receive, store and disseminate information for public use. These include the library, the research department, the public relations department, the journals' office, and the ICT department. The Hansard is regarded as the only source of parliamentary information, but many more documents are valuable 
to the public (Mataure 2003). The problem is that the PoZ has insufficient capacity to disseminate parliamentary information due to a lack of financial, material, and human resources. As a result, constituents do not know what happens in parliament because the information is not made available to them. At the same time, Members of Parliament (MPs) should be fully aware of what is taking place in their constituencies in order to carry out their work effectively. Two-way communication between MPs and their constituents is therefore an urgent matter. DPs have the potential to improve communication by disseminating parliamentary information to constituents, and providing feedback to MPs from constituents.

The aim of the study was to identify practical ways in which Zimbabwe's PCICs can be improved as a result of insights based on new research that focuses on the contributions of DPs. This article analyses the contributions made by the UNDP and INASP as DPs that played major roles in improving the dissemination of parliamentary information to constituents in Zimbabwe. It identifies the challenges they face, and makes recommendations to continue to improve the dissemination of parliamentary information to constituents. There were some limitations of the study. For instance, although the findings and conclusions of the study may be useful to other countries, they cannot be generalised as being valid for them. Zimbabwe's political and economic environment differs sharply from those of other developing countries.

\section{LITERATURE REVIEW}

Parliaments generate a large amount of information that is intended for public consumption. Obholzer (2011) states that parliamentary information includes:

Information about parliament's roles and functions, and information generated throughout the legislative process, including the text of introduced legislation and amendments, votes, the parliamentary agenda and schedule, records of plenary and committee proceedings, historical information, and all other information that forms part of the parliamentary record, such as reports created for or by parliament.

In recent years, DPs have recognised the importance of parliaments for democratic governance due to their roles in law-making, executive oversight, and in representing citizens and their interests (USAID 2006). Because people are now demanding more information to be disseminated by parliaments, several DPs have begun to facilitate, promote and strengthen constituents' engagement in the parliamentary processes, as well as to provide access to information about parliamentary activities.

In the 1990s, CSOs as DPs started to disseminate parliamentary information in response to gaps in social services caused by structural adjustment programmes in developing countries (Mataure 2003). Several studies have documented the work of CSOs. Zinecker (2011), for example, locates them in civil society as a sub-system surrounded by the economy, state and family in a social system. CSOs are 'sovereign- 
free, non-state, not for profit, and voluntary organisations formed by people in the social sphere of civil society' (Seligman 1992). They are also regarded, in another representation, as a third sector existing alongside and interacting with the state and private industry (UNDP 2001). Some of their key features are that they are separate from the state and the market, and they are formed by people who have common needs, interests and values, such as tolerance, inclusion, cooperation and equality.

CSOs include non-governmental organisations (NGOs), independent mass media, think-tanks, universities, and social and religious groups. In a democracy, CSOs respect the law and the rights of individuals and other groups to express their interests and opinions. The word 'civil' implies tolerance and the accommodation of pluralism and diversity. Keane's (2003) study shows that CSOs establish ties with state organisations to pursue their collective interests and engage in activities of public importance. They draw their membership from the community, neighbourhood and social connections and provide institutional vehicles beyond the ties of the immediate family to collectively relate to the state or market.

DPs have been contributing to the dissemination of parliamentary information for many years. According to Moore and Steele (1991), they provide constituents with parliament-generated information in order to support them as members of society and as consumers. Moore and Steele (1991, 28-29) add that DPs:

- lobby for equity and favourable policies;

- act as an intermediary between communities and parliament;

- reach remote areas poorly served by constituency information centres;

- provide services that may be less expensive and more efficient;

- provide technical skills on a range of issues;

- innovate and recommend good practices; and

- contribute to public understanding and enhancing public information.

To this list Campbell and Stapenhurst (2005) add supporting MPs and parliament staff, supporting operational and recurrent costs, and carrying out field visits; while Tostensen and Amundsen (2010) identify physical infrastructure, institutional capacities and structures, parliamentarians' skills, and performances.

The involvement of African constituents in parliamentary information services emerged as a result of the Association of Parliamentary Libraries for Eastern and Southern Africa (2004), and the Africa Parliamentary Knowledge Network (2009). DPs identified the gap and started mapping the landscape of parliamentary strengthening, drawing on the Paris Principles guidelines (Hudson 2007). The Global Centre for ICT in Parliament and Parliamentary Monitoring Organisations (PMOs) represent recent types of CSOs that monitor more than 80 national parliaments worldwide. PMOs are: 
Citizen-based groups that monitor the functioning of parliaments or their individual members, often seeking to facilitate and promote public knowledge and their participation in parliamentary processes. They collaborate in strengthening several information related components that includes citizen engagement in the legislative process, and access to information about parliaments and their work. (Global Centre for ICT in Parliament 2012, 24)

This collaboration and promotion has led to the declaration of Parliamentary Openness (National Democratic Institute 2002). The UNDP is a key player in the field of parliamentary development. The UNDP's institutional reform work focuses on procedures and the internal organisation of parliaments to provide the basic functional capacity. This includes support for transcription services, libraries and information systems; publication of handbooks on poverty reduction; and the relationship between parliaments and the executive, and parliaments and CSOs (World Bank Institute 2007). The UNDP has been working together with the PoZ to identify the information needs of citizens. Over the years, the UNDP has consulted and coordinated the activities of other DPs in Zimbabwe. DPs engaged in parliamentary activities include the Public Affairs and Parliamentary Support Trust, the Women in Politics Support Union, the Konrad Adenauer Foundation, the Zimbabwe Election Support Network, the Civil Education Network Trust, the Crisis in Zimbabwe Coalition, the Human Rights Trust in Southern Africa, and the Zimbabwe Evidence Informed Policy Network. The activities of these partners are coordinated by the Parliamentary Programme Coordinating Unit.

As another example of a DP, the United Nations Department of Economic and Social Affairs (UN/DESA 2005) has identified the lack of capacity as a gap in disseminating parliamentary information to constituents. Other gaps that were identified include:

- Lack of strategic vision and managerial skills;

- Lack of qualified professional staff;

- Lack of value-added information services;

- Lack of interoperability standards;

- Weak role of Parliaments in promoting the Information Society; and

- Lack of coordination of Parliamentary Development Assistance. (UN/DESA 2005)

To improve information dissemination, UN/DESA is supporting the Africa i-Parliaments Action Plan, which incorporates a parliamentary informatics programme. A number of African parliaments, including the PoZ, participated in the Africa i-Parliaments Action Plan. The parliamentary informatics programme aims at supporting the dissemination of parliamentary information and public participation 
in parliamentary activities. It applies ICT to the collection, collation and organisation of parliamentary information.

World e-Parliament Reports have provided guidelines to parliaments to improve their information dissemination programmes. For example, the World e-Parliament Report for 2008 shows how parliaments can use ICTs to help them fulfil their responsibilities and to connect with their constituents. This report also shares lessons learned and good practices from different regions of the world. The World e-Parliament Report for 2010 recommends that legislatures should harness the potential benefits of ICTs for their work and establish key goals and priorities. This report suggests ways to overcome ICT obstacles in parliamentary settings. The World e-Parliament Report for 2012 documents efforts by legislatures to use ICT to support their constitutional functions. This Report is the third in a series of surveys that began in 2007. The World e-Parliament Conferences for 2013 and 2014 present evaluations of how parliaments have been using ICTs to improve their activities.

INASP (2011) refers to the strengthening of parliamentary information services as Evidence Informed Policy Making. INASP works with a range of policy makers to build a demand for research information. To achieve this, INASP works with information professionals to improve their ability to provide relevant information to policy makers. By strengthening links between policy makers and information professionals, and building capacity for information, the aim is to help formulate poverty reduction policies based on credible research evidence (INASP 2011). For INASP (2011), capacity building refers to development work that strengthens the ability of community organisations and groups to build their structures, systems and people's skills that they are better able to define and achieve their objectives, consult and plan, manage community projects, and participate in partnerships and community enterprises.

The Inter-Parliamentary Union (2006) also helps to strengthen parliaments around the world through reforming parliamentary information services. This involves providing advisory services, developing the library, archives, documentation, research, press, public information services, staff training, and promoting the use of new ICTs in parliamentary processes. These developments have made it necessary for parliaments to review the way they do business. A study that evaluated the performance of Zimbabwe's PCICs showed that the DPs play important and valuable roles in disseminating parliamentary information to constituents (Munyoro 2014). The focus of the article now shifts to an analysis of the contributions by the UNDP and INASP, and the challenges they face in Zimbabwe.

\section{METHODOLOGY}

A mixed-method approach (Ngulube 2010) was used in the study to allow for concurrent analysis of both quantitative and qualitative data. Reliable and valid data is not of much use, unless the tools to analyse and interpret the data are used with 
care and expertise. According to Babbie and Mouton (1998, 101), the function of data analysis is to interpret the collected data for the purpose of drawing conclusions that reflect the interest, ideas and theories that initiated the inquiry. There is no single or best way of analysing data (Hagan 2000). For the current study, the data from questionnaires was analysed using the Statistical Package for the Social Sciences (SPSS). Analysis of qualitative data adopted the framework developed by Miles and Huberman (1994) to describe and classify the major phases of data analysis by sorting it into themes and sub-themes, such as accessibility to services, visits, weaknesses, and challenges faced in the operation of PCICs.

The following target groups were identified because they can shed light on the contributions and challenges of DPs in disseminating parliamentary information to constituents:

- Members of Parliament (MPs) are the political leaders in constituencies and represent them in parliament. DPs work directly with MPs and make donations to constituency activities directly through the MPs, by-passing the PoZ.

- Constituents are citizens residing in a legislator's constituency boundaries, and are the intended beneficiaries of parliamentary information that is disseminated with the help of DPs.

- Development Partners (DPs) have been involved with PCICs and the dissemination of parliamentary information in one way or another in Zimbabwe. For example, SIDA funded the first PCIC data collection; the UNDP bought furniture and ICT equipment for PCICs and paid salaries for OAs and rates for rented offices. DPs also provided grants to train PoZ officers, including OAs to equip them with basic skills to search and disseminate parliamentary information.

- The Administration of Parliament is well-informed on issues relating to parliamentary reforms, and was selected for interviews about DPs.

- Officers of Parliament are located in the ICT, PR, Research and Human Resource departments. They participated in training programmes supported by grants from DPs and provided feedback on the benefits of DP support.

- PCIC Office Assistants (OAs) are responsible for the day-to-day PCIC operations. They keep diaries of events for MP programmes, schedule meetings and serve the public or visitors to the PCIC. Since they are locals, they have a better understanding of local DPs, communities, and cultures. 


\subsection{Sampling techniques}

The study used purposive sampling in some instances, and random sampling in others. This was an attempt to keep costs to a manageable level, and to avoid too much focus on convenient geographical regions, such as those close to Harare. This was also done to avoid bias and damaging effects on reliability. A purposive or judgmental sample was selected based on the knowledge of a population and the purpose of the study (Yates 2008). Random sampling techniques provide the probability in the choice of elements from the sampling population. Saunders, Philip and Thornhill (2003) describe how a random sample can provide satisfactory and valid surveys for researchers.

Purposive sampling was used to choose the geographic province for the first stage of selection in the sample plan. This decision was based on established views of which districts are typical or representative in some sense or context. For instance, most Mashonaland districts were typically Zimbabwe National Union Patriotic Front (ZANU PF) districts, while the metropolitan and Matabeleland provinces were typically Movement for Democratic Change (MDC), and some were typically sway provinces. Neither political party was in control of sway provinces.

The provinces were first stratified using the predominant characteristics, such as rural/urban; a geographical population spread; and a random sample of constituencies, selected in any of a variety of ways chosen from each stratum in a proportionate way. Stratification was chosen as it greatly decreased the likelihood of selecting an odd sample. With the stratified sample, every constituency in the sample frame had a chance of selection that was unbiased and unaffected by subjective opinion. The total number of registered voters was obtained from the Report on the Delimitation Exercise for the 2008 Harmonised Election. For example, of the ten provinces, Mashonaland Central had 488477 registered voters from 18 constituencies. There are currently seven PCICs operating; and four of these PCICs were sampled. The four sampled PCICs had 106904 registered voters.

\subsection{Overall response rates}

A comprehensive picture of the contributions and challenges of DPs in the dissemination of parliamentary information emerged from the data collected through surveying these target groups. The Administration of Parliament (represented by the Clerk of Parliament), Officers of Parliament and OAs, and the Parliamentary Programme Coordinator DPs at parliament representing all development partners are well-informed about PCICs, and were respondents in the in-depth interviews. Questionnaires were used to obtain data from MPs (see Table 1). 
Table 1: $\quad$ MPs' questionnaire responses by province $(\mathrm{N}=20)$

\begin{tabular}{|l|l|l|l|l|}
\hline Province & Frequency & Percentage & $\begin{array}{l}\text { Valid } \\
\text { percentage }\end{array}$ & $\begin{array}{l}\text { Cumulative } \\
\text { percentage }\end{array}$ \\
\hline Masvingo & 4 & 20.0 & 20.0 & 20.0 \\
\hline Manicaland & 4 & 20.0 & 20.0 & 40.0 \\
\hline Harare & 3 & 15.0 & 15.0 & 55.0 \\
\hline Mat South & 1 & 5.0 & 5.0 & 60.0 \\
\hline Mash Central & 3 & 15.0 & 15.0 & 75.0 \\
\hline Midlands & 3 & 15.0 & 15.0 & 90.0 \\
\hline Mash East & 2 & 10.0 & 10.0 & 100.0 \\
\hline Total & $\mathbf{2 0}$ & $\mathbf{1 0 0 . 0}$ & $\mathbf{1 0 0 . 0}$ & \\
\hline
\end{tabular}

Twenty out of 25 questionnaires were returned by MPs, whereas 15 out of 25 questionnaires were returned by OAs. Constituents completed and returned 255 out of 625 questionnaires. The low response rate was due to a high degree of mistrust of researchers by constituents after the 2008 political backlash. A number of people in Zimbabwe suffered political backlash during and after the 2008 harmonised elections. This was followed by a period of mistrust and fear amongst citizens and MPs. The fear translated into scepticism and some constituents were afraid to complete the questionnaires because Zimbabwean elections were being held close to the period of data collection. Even though reference letters authorising the study were produced, MPs and constituents were reluctant to complete the questionnaires. Also, due to some legal instruments in the country, the researcher faced resistance in obtaining relevant information from some key sources, during the data collection exercise. For instance, the researcher had to forego using focus groups, because this would have required Police clearance, which is a difficult and onerous task.

Observation methods were also used to collect data during visits to PCICs to study constituents' behaviour in their natural setting. Document analysis was used to reinforce and compare official records with participants' verbal accounts. Documents analysed included OAs' monthly and annual reports, parliamentary reforms reports, DPs' and administration of parliament reports. In addition, training evaluation reports provided data from information literacy course participants. A total of 60 out of 78 PoZ Officers who participated in the information literacy training responded in the evaluation forms and commented on DPs. 


\section{RESULTS AND DISCUSSION}

The data on the contributions and challenges of the UNDP and INASP in the dissemination of parliamentary information in Zimbabwe are discussed in this section.

\subsection{The United Nations Development Programme}

The study data showed that the UNDP supports a number of parliamentary projects, including PCICs that disseminate parliamentary information. The UNDP provided support through:

- identifying information needs of constituents;

- providing ICT equipment;

- updating the Constituency Information Profile Database (informatics database); and conducting PCIC outreach and verification of assets.

The data gathered through observation, document analysis, and interviews revealed that the UNDP has supported PCICs from the initial start-up funding for PCIC requirements. The Parliamentary Programme Coordinator stated that the unit provides administrative support to the Clerk of Parliament to coordinate and implement Parliamentary Support Programmes, as well as to coordinate the activities of other development partners involved with parliamentary reforms. The specific activities of the UNDP in facilitating information dissemination are discussed below.

\subsubsection{Identifying information needs of constituents}

The information needs of constituents identified in a study of PCICs corroborate the findings of the feasibility study by Mutaviri and Ncube (2003). The reasons for visiting PCICs are summarised in Table 2. The UNDP's involvement in the PCIC project was to fund the feasibility study into constituents' information needs. The strongest reason for PCIC visits by constituents with a frequency of $49(20.2 \%)$ was to collect and read the Hansard; 33 (13.6\%) visited for current awareness services (CAS); 31 (12.8\%) visited to check for relevant information; 27 (11.2\%) wanted to see the MP and collect the Hansard; 14 (5.8\%) were interested in getting information on project funding; $13(5.4 \%)$ came for updates on legislative/parliamentary affairs; $12(5 \%)$ wanted to learn about developments in their constituencies and in the PoZ; another $12(5 \%)$ came for the Hansard and press; and $10(4.1 \%)$ wanted reading materials, such as newspapers and magazines. Seven (2.9\%) constituents came for various/other reasons, such as constituency information, grievance submission, livelihood information/interest, PCIC operations, students and teacher research, Internet access and to deliver invitation letters to the MP. 
Table 2: Constituents' information needs $(\mathrm{N}=255)$

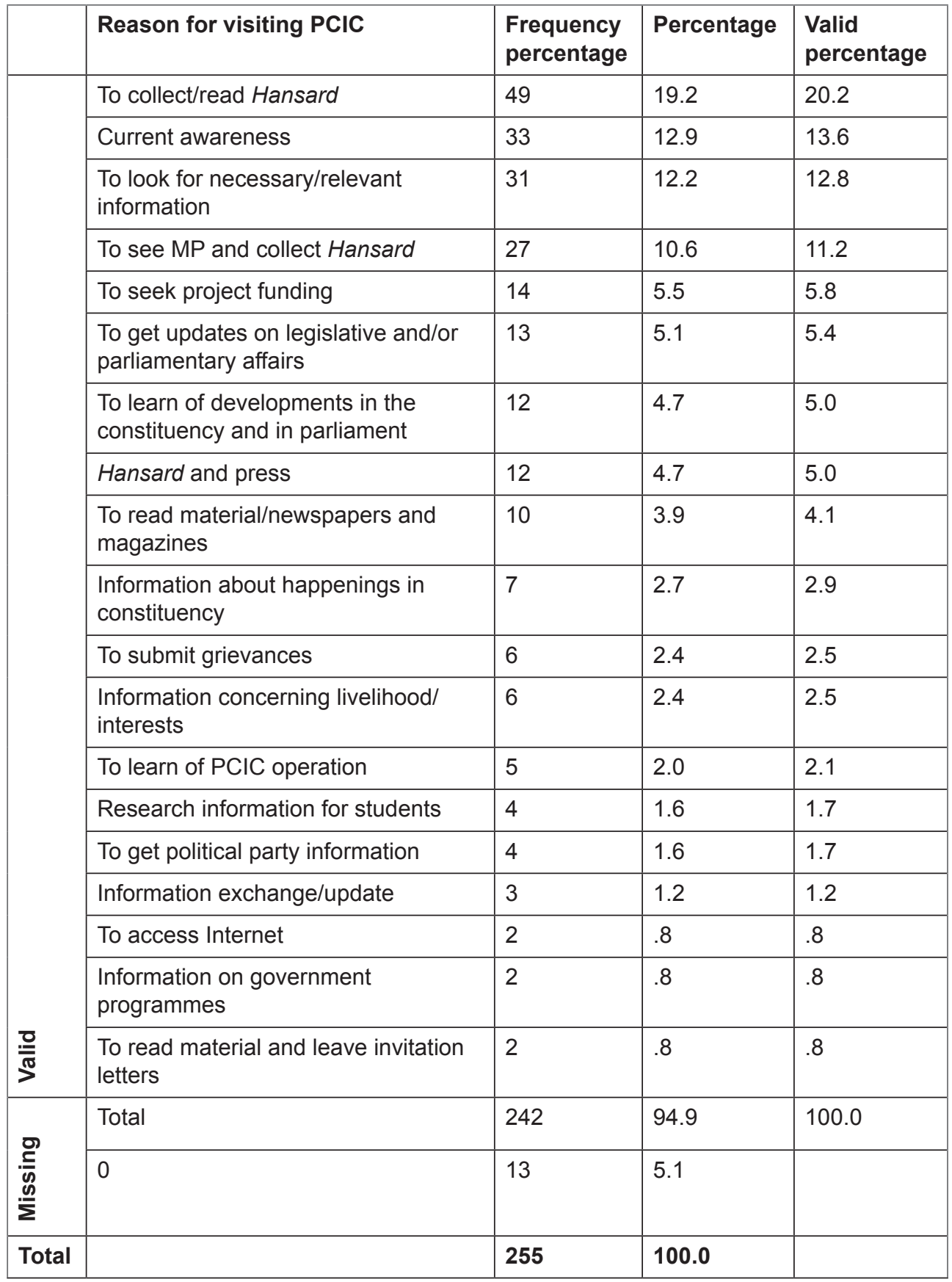


The Hansard is the most popular publication consulted at PCICs. The data showed that the Hansard, Internet access, newspapers, journals, database, and bills all rated above 80 per cent in terms of other information sources, signifying an emphasis on up-to-date information, and on Current Awareness Services (CAS) in general. The constituents also want a global identity, as signified by the need to access Internet and newspapers for global information needs.

The data revealed that the availability of non-book materials and photocopying services are also significant. Photocopying can assist constituents in the reproduction of PCIC publications. Information dissemination in suitable formats such as audio materials and audio visuals were ranked at 60-70 per cent in importance. This shows that constituents prefer formats other than print, making the 'repackaging information' necessary. Information repackaging and simplification of information to match constituent levels are therefore important functions for the informatics database administrator.

The collection of data on reasons for visiting PCIS was to assess whether there were enough information materials available for the number of visiting constituents, and whether the information was up-to-date. The Administration of Parliament confirmed they are not in a position to supply the number of Hansard copies required, so these are limited to 50 copies per constituency. This number cannot meet the demand because constituencies have thousands of people. The 2008 World e-Parliament Report already observed this and urged DPs to assist parliaments, and to address matters relating to the digital divide and access to technology by all citizens, multiple languages, literacy, and people living with disabilities.

These information requirements were identified through data obtained from constituents who use PCICs that were set up by the PoZ in partnership with DPs. The information requirements form the basis of what DPs have to deliver to constituents. The main challenges for the UNDP and other DPs, as reflected in this data, are that the parliamentary information disseminated by the PCICs is insufficient, out-dated, and not in suitable formats.

\subsubsection{Providing facilities and services}

Library services at PCICs were lacking because there was no separate room set aside for this purpose. Other facilities, such as computers, printers, desks, chairs and pamphlets were provided. The UNDP donated computers to PCICs, but as shown in Figure 1, most (77\%) of the OAs responded that PCICs are not sufficiently equipped to disseminate information to constituents because:

- Furniture and equipment are outdated, broken and obsolete.

- Most computers are non-operational. According to OAs, the computers have not been serviced for more than two years.

- Resources such as consumables are lacking. 
- No photocopying services are available.

- No Internet connection is available.

- Insufficient space is provided. Some of the PCIC offices are so small that a sizeable number of visitors cannot be accommodated at any given time.

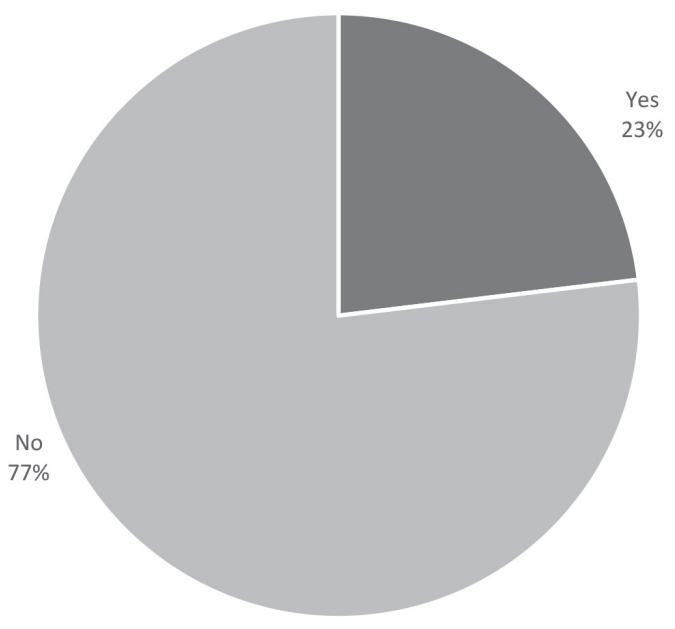

Figure 1: Are PCICs well equipped?

Whereas the lack of resources affects all PCICs, insufficient space does not. Some PCICs have bigger office space that is underutilised. The PoZ has not been able to fully utilise the equipment donated by the UNDP. Another challenge that was identified from the data was the lack of continuity. The PoZ could not afford to continue paying the rent and rates for buildings after withdrawal of the UNDP initial funding. This resulted in a number of PCIC offices closing. Other well-documented challenges are found in the evaluation reports. For example, De Vrieze and Murupa (2012) identified that capacity building of OAs has not been given enough attention, and that it lacks support from management. Similar challenges have been identified in the Parliament of Zimbabwe's Constituency Audit Committee Report (2011), but with no solution in sight.

The political conditions in a country cannot be separated from the dissemination of parliamentary information to constituents. The data from the study revealed that political interference hampers the work of DPs in disseminating parliamentary information to constituents. In some instances, DPs withheld funding when they were in disagreement, and this affected the successful operation of programmes. There is a grave danger for the dissemination of parliamentary information when there are divisions among DPs and political parties, and this is a particularly thorny challenge for DPs. 


\subsubsection{Asset use and verification}

The UNDP conducted PCIC outreach programmes in order to assess the use of computers and to verify assets such as computers that it had donated to PCICs. The study data revealed that computer use at PCICs involved basic word processing primarily for:

- typing of minutes and reports (86\%); and

- record-keeping and information storage (81\%).

Only a small percentage (11\%) of OAs use computers because of the lack of basic computer training. Table 3 shows the main uses of computers at PCICs.

Table 3: Main uses of computers at PCICs

\begin{tabular}{|l|l|}
\hline Main uses of computers at PCICs & Aggregate/Multiple responses \\
\hline Typing reports and minutes & $86 \%$ \\
\hline Record keeping/Information storage & $81 \%$ \\
\hline MP reports on constituency activity & $22 \%$ \\
\hline Data analysis & $11 \%$ \\
\hline
\end{tabular}

Although the UNDP donated computers and printers to the PoZ for use at PCICs, it did not service them. The researcher observed that computers at most PCICs are not functioning, and are obsolete. Some of the computers were acquired 10-12 years ago and are beyond repair, and should be replaced. Of the computers that are working, none are connected to the Internet. Printers and fax machines are also not functioning. Some of the OAs administering PCICs indicated that they use their own laptops and personal e-mail addresses. Others had neither personal laptops, nor e-mail addresses. Although OAs have submitted several reports to the PoZ about the state of equipment, maintenance has not been carried out because the ICT department lacks the capacity to do so.

This is certainly a challenge for the UNDP in its efforts to improve the dissemination of information to constituents through PCICs. The PoZ has neither the capacity to utilize the computers to their full potential, nor to service them. Most of the computers donated by DPs like the UNDP are lying idle at the PoZ, rendering this contribution ineffective.

\subsubsection{The informatics database}

The PoZ is among a number of parliaments that apply parliamentary informatics. Parliamentary informatics refers to the application of information technology to the documentation of parliamentary activity (Mandelbaum 2011). The UNDP has 
continued to support PCICs by up-dating the Constituency Information Profile Database. This concept is applied not only in Zimbabwe. In Western Australia an information database system (Battye 2004) was put in place through cooperation between the Western Australian government and community organizations. The purpose of the database is to provide referral services to other organisations in order to satisfy client information needs.

The UNDP has on several occasions funded the updating of the PoZ informatics database. However, most of the OAs claimed that they were not trained in operating the informatics database. Figure 2 shows that 58 per cent of OAs have not been trained at all in aspects of the informatics database. According to documents from the public relations department, OAs were last trained in 2003. Those who were trained acquired only a basic understanding about the uses of the database.

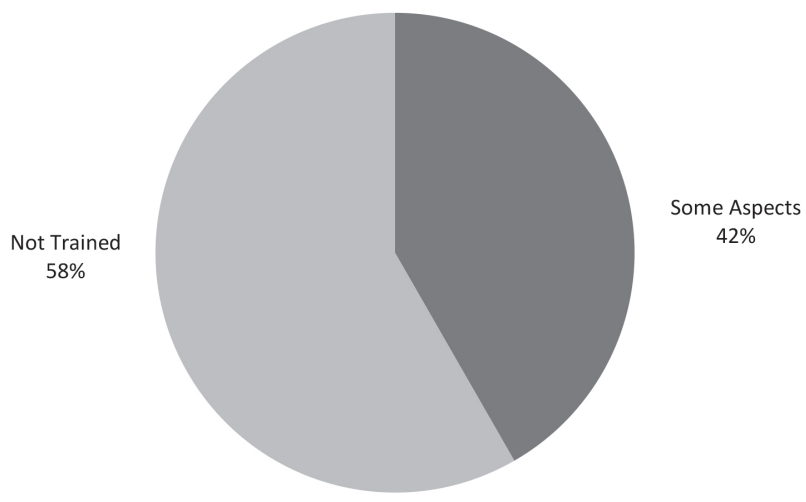

Figure 2: Informatics database training (OAs)

At the same time, the informatics database has become a rapidly growing requirement for parliamentary monitoring, and as a democratic-participation tool to aggregate information and to facilitate citizen participation in parliamentary processes. Although informatics databases provide valuable socio-economic data about constituencies, there are gaps because the database is not updated regularly. This is linked to the PoZ's lack of capacity to maintain computers that were donated by the UNDP, and the lack of regular training programmes for OAs. The underutilisation of computers and the informatics database is hindering the dissemination of parliamentary information through the use of ICTs.

\subsection{The International Network for the Availability of Scientific Publications}

INASP has not been directly involved in the PCIC project, but has assisted with providing capacity building to officers of parliament to improve the dissemination of 
parliamentary information. The study data showed that in 2010, INASP sponsored information literacy (IL) training workshops to improve access to and effective utilisation of the information resources in the PoZ. Seventy-eight officers of parliament (see Figure 3) participated in the training. The principal aim was to raise participants' awareness and to equip them with skills to locate, understand, evaluate, utilise and convey information. Participants obtained hands-on skills to effectively search for information, manipulate online tools and other associated applications to improve access to, and effective use of, the kinds of information needed to support evidence-based policy-making in Parliament. The training was expected to cascade to MPs, and INASP expressed a willingness to sponsor the training of MPs in future, with a focus on strengthening democracy.

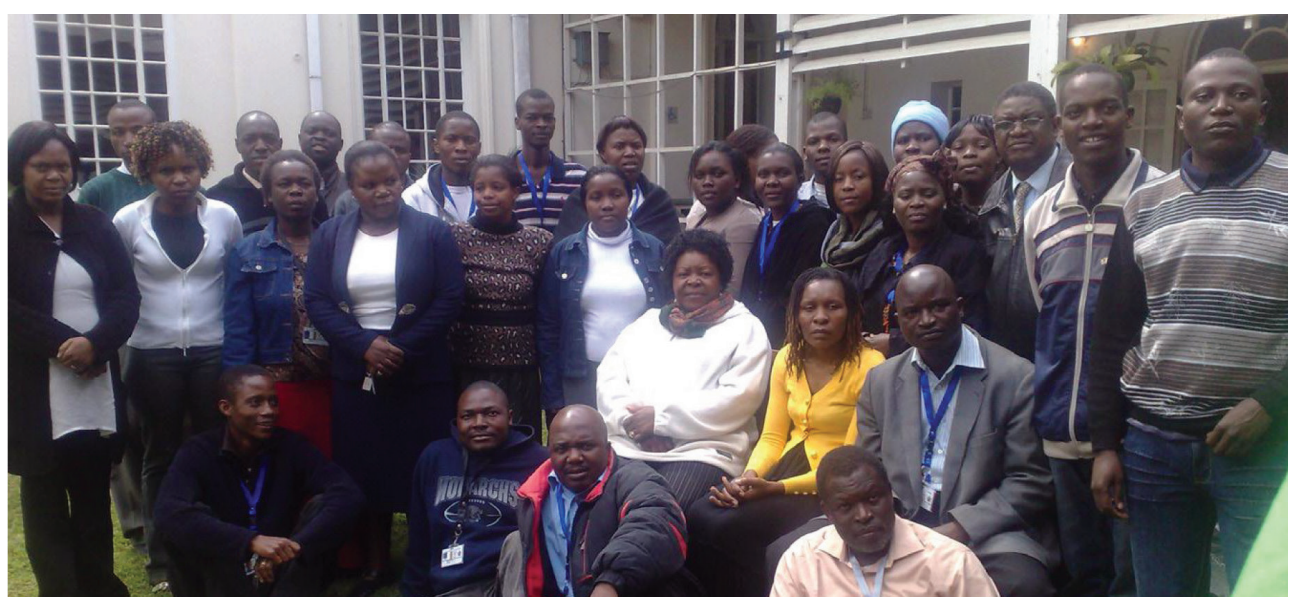

Figure 3: Participants at the Parliament of Zimbabwe IL training (2010)

The IL training consisted of lectures, discussion groups, and hands-on activities. The majority of the participants revealed that IL training was critically important to improve their search for information, and to increase their awareness of the value of IL. The officers of parliament responded positively to the training as indicated in the following examples of participants' responses:

- The training provided ... synergies among librarians, ICT personnel and researchers so that they collaborate to improve access and utilisation of scientific electronic information resources in Parliaments.

- I am now aware of a lot of different search engines and online resources other than the ones I was familiar with and this will expose me to wider access to information.

- I will be able to assist MPs more effectively particularly with my searching skills. 
- I have been using time-consuming techniques to search the web but now I can employ strategic skills that I have learnt from this workshop.

- Such support from donors must continue and we should have another training workshop.

- I can now use alternative gateways to information and joining online discussion forums will increase access to more current and relevant information.

INASP is still cooperating with the PoZ through the Zimbabwe Evidence Informed Policy Network. In implementing capacity building programmes, INASP faces challenges such as the lack of appreciation by policy makers about the value of information in development issues. At the PoZ this has led to the lack of sustained follow-up and capacity-building programmes.

\section{CONCLUSION}

DPs play an important democratic role in disseminating parliamentary information to constituents. By partnering with DPs, the PoZ is positioned to address information gaps between parliament and constituents. The DPs' collaboration with the PoZ in disseminating parliamentary information has contributed significantly to building democracy in Zimbabwe. Their activities have revolved around funding research, capacity building, technical assistance, advocacy, and the actual delivery of parliamentary information to constituents. They still, however, face challenges related to the political and socio-economic conditions in Zimbabwe. Of particular concern are challenges regarding political partisanship.

\section{RECOMMENDATIONS FOR DPS TO IMPROVE THE DISSEMINATION OF PARLIAMENTARY INFORMATION}

The recommendations identified in the article target those areas where the dissemination of parliamentary information can be improved. From the discussions above, the following recommendations can be made to improve the dissemination of parliamentary information by DPs:

In order to ensure their collaboration with the PoZ, NGOs should desist from being aligned to political parties. This could be achieved through continuous education and outreach programmes to promote public awareness about political partisanship. These could include the use of various media, such as pamphlets, leaflets, radio and television. DPs should spread their capacity building programmes to cater for OAs. The majority of OAs do not have the basic information skills to service constituencies. Capacity building programmes should be regular and on- 
going activities. The resource implications for implementing these recommendations require further investigation.

\section{REFERENCES}

Association of Parliamentary Libraries of Eastern and Southern Africa. 2004. www.morewords. com/word/aplesa (accessed September 12, 2013).

Africa Parliamentary Knowledge Network. 2009. Strengthening the cooperation among parliamentary libraries in the framework of the Africa Parliamentary Knowledge Network. www.apkn.org/conference-documentation/rome-december2009 (accessed September 20, 2014).

Babbie, E. and J. Mouton. 1998. The practice of social research. Oxford: University Press.

Battye, J. S. 2004. Collection development policy and information database policy. Perth: Library and Information Service of Western Australia.

Campbell, M. and F. C. Stapenhurst. 2005. Developing capacity through networks: Lessons from anticorruption parliamentary coalitions. World Bank Institute Working Paper. documents. worldbank.org/curated/en/docsearch/author/m124862 (accessed February 13, 2015).

De Vrieze, F. and R. Murupa. 2012. Evaluation of the UNDP parliamentary support project in Zimbabwe and recommendations. Final Evaluation Report. UNDP.

Global Centre for ICT in Parliament. 2008. World e-Parliament Report. Report of the United Nations Department of Economic and Social Affairs and the Inter Parliamentary Union through the Global Centre for ICT in Parliament.

Global Centre for ICT in Parliament. 2012. World e-Parliament Report. Report of the United Nations Department of Economic and Social Affairs and the InterParliamentary Union through the Global Centre for ICT in Parliament.

Granickas, K. 2013. European Public Sector Information Platform, Parliamentary informatics: What data should be open and how multi-stakeholder efforts can help parliaments achieve it. Topic Report No. 05/2013.

Hagan, F. E. 2000. Research methods in criminal justice and criminology. 5th ed. Boston, MA: Allyn and Bacon.

Hudson, A. and C. Wren. 2007. Parliamentary strengthening in developing countries. Report prepared for the Department for International Development (DFID). London: ODI. http:// www.gsdrc.org/go/display\&type=Document\&id=2809 (accessed August 23, 2013).

INASP see International Network for the Availability of Scientific Publications.

International Network for the Availability of Scientific Publications. 2011. Evidence based policymaking. www.inasp.info/uploads/filer-public (accessed April 11, 2013).

Keane, J. 2003. Global civil society? Cambridge: Cambridge University Press.

Mandelbaum, G. 2011. Strengthening parliamentary accountability, citizen engagement and access to information: A global survey of parliamentary monitoring organisations. www ndi. org/.../governance-parliamentary-monitoring-organisations-survey (accessed November 12, 2012). 
Mataure, M. 2003. Public Affairs and Parliamentary Support Trust. Paper commissioned by Training and Research Support Centre, Harare, Zimbabwe, August 2003.

Miles, M. B. and A. M. Huberman. 1994. Qualitative data analysis: An expanded sourcebook. Thousand Oaks, CA: Sage.

Moore, N. and J. Steele. 1991. Information-intensive Britain: A critical analysis of the policy issues, 28-29. London: Policy Studies Institute.

Munyoro, I. 2014. An evaluation of the performance of Zimbabwe's Parliamentary Constituency Information Centres and their future improvement. DPhil diss., University of Pretoria, Pretoria.

Mutaviri, T. and A. Ncube. 2003. A report on the feasibility study on the establishment of Parliament Constituency Information Centre. Harare: PoZ.

National Democratic Institute. 2002. Constituency handbook for elected representatives in Namibia. http://www.accessdemocracy.org/library/1376-na-constituencyhdbk (accessed January 23, 2011).

Ngulube, P. 2010. Mapping mixed methods research in library and information science journals in Sub-Saharan Africa. International Information and Library Review 42: 252-261.

Obholzer, L. 2011. A call to members of the European Parliament: Take transparency seriously and enact the legislative footprint CEPS Policy Brief No. 256, October 2011. http://aei.pitt. edu/32965/ (accessed September 9, 2011).

Parliament of Zimbabwe. 2011. Constituency Audit Committee Report 2011. Harare: PoZ.

Parliament of Zimbabwe. 2013. Constituency Audit Report 2013. Harare: PoZ.

PoZ see Parliament of Zimbabwe.

Seligman, A. B. 1992. The idea of civil society. Princeton, NJ: Princeton University Press.

Tostensen, A. and I. Amundsen. 2010. Support to legislatures. Bergen: Chr. Michelsen Institute. http://www.norad.no/en/tools-publications/evaluations (accessed June 12, 2013).

UN/DESA see United Nations Department of Economic and Social Affairs.

United Nations Department of Economic and Social Affairs. 2005. Africa i-Parliament Plan. www.un.org/desa (accessed September 11, 2014).

Yates, S. J. 2004. Doing social science research. London: Sage.

Zimbabwe Electoral Commission. 2008. Report on the delimitation exercise for the 2008 harmonised elections, January 2008.

Zinecker, H. 2011. Civil society in developing countries: Conceptual considerations. Journal of Conflictology 2(1): 1-3. http://journal-of-conflictology.uoc.edu (accessed September 15, 2014).

\section{ABOUT THE AUTHORS}

ISAIAH MUNYORO (PhD) is the Director of Library Services at the Parliament of Zimbabwe. He completed his PhD (Information Science) at the University of Pretoria (UP), Pretoria, South Africa, in 2015 and is currently a post-doctoral research fellow 
in the Department of Information Science at UP. In addition, he teaches part-time media studies at various institutions in Zimbabwe.

ARCHIE DICK is a professor in the Department of Information Science at UP. He has been a visiting professor at Wayne State University, Detroit, MI, and the University of Illinois, Urbana-Campaign, IL, United States. 